\title{
Reconstruction and modernization of industrial parks
}

\author{
Petr Graboviy ${ }^{1, *}$
}

${ }^{1}$ Moscow State University of Civil Engineering, 26, Yaroslavskoye Shosse, Moscow, 109377, Russia

\begin{abstract}
The construction of the industrial park is organized in accordance with the program management method, which identifies independent startup industrial and construction complexes that determine the order in which preparatory and basic works are carried out, the calendar construction timeframe and the sequence for entering construction queues taking into account the timely supply of equipment and structures, regulatory requirements for material and labor resources, as well as means of mechanization. In the organizational form of reproduction, carried out during the reconstruction of the industrial real estate of the park, surveys are conducted on the technical condition of the structures, intrasurface and intrasite vehicles and communications, equipment and engineering networks, production conditions and construction and installation works. The article presents an example of assessing economic efficiency of the business plan for organizing the construction of an oil pipeline, which is part of an industrial (industrial) park, in the section from 1569 to $1978 \mathrm{~km}$ in the Mari Republic and the southern part of Kirov Oblast, with natural borders from $r$. Vyatka to $r$. Vetluga diameter of the pipeline is $1020 \mathrm{~mm}$.
\end{abstract}

\section{Introduction}

In accordance with the official data of the State Statistics Committee of the Russian Federation, section 14, the basis of the industry sphere is represented by the industry: fuel and energy; ferrous and nonferrous metallurgy; chemical and petrochemical industry; machine building and metalworking; forestry, woodworking and pulp and paper industry; building materials industry; light industry; food industry; medical industry.

Order No. 143 of the Ministry of Industry and Trade of the Russian Federation of January 30, 2015 "On Approving Guidelines for Preparing an Application for Reimbursement of Costs for Creating an Industrial Park or Technopark Infrastructure, Except for a High-Tech Technopark" defines the specialization of an industrial real estate project the quality of a multi-project industrial park for implementation, namely: metallurgy, machine-tool construction, heavy engineering, the military-industrial complex, light industry; shipbuilding industry; marine equipment; radio electronic industry; chemical technology industry; timber industry complex; the industry of conventional weapons, ammunition and special chemistry; aviation industry; pharmaceutical and medical industry; transport and special machinery [1].

\footnotetext{
${ }^{*}$ Corresponding author: osun_kaf@mgsu.ru
} 
The effectiveness of managing such projects largely depends on the relationship of the project participants in all phases of its life cycle.

All the variety of processes taking place at present in the management of industrial real estate projects can be represented as a set of technical, organizational and economic tasks $[2$, $3]$.

In accordance with the National Standard GOST R56301-2014 "Industrial parks. Requirements" industrial real estate is characterized by the following types of parks:

- industrial park of the "greenfield" type, created on a previously undeveloped land plot, as a rule, not provided with engineering and transport infrastructure at the time of the start of the project;

- "brownfield" industrial park, created on the basis of previously existing enterprises or production facilities provided with engineering and transport infrastructure, in respect of which, as a rule, reconstruction and / or major repairs were carried out and / or carried out.

Studies of the development of industrial parks in Russia [4] show a significant dynamics of the development of this segment of industrial construction. In accordance with the data of the Association of Industrial Parks on 2017 [2] for the period from 2013 to 2016. the number of industrial parks increased by more than $80 \%$, from 80 to 146 . The growth is due to the existing parks, their number has more than doubled over three years, from 45 to 92 . In turn, the number of parks created remains stable from year to year and ranges from 44-56 projects.

The increase in the number of parks is accompanied by their renewal - a number of projects have ceased their activities. The main reasons include: changing the format of doing business, closing down unclaimed parks, or postponing implementation dates to later years. In total, over the last year, 10 out of 120 created and existing industrial parks have ceased to exist. They were replaced by 36 new multiprojects during this time. 9 more created multiprojects have become active parks.

The upward trend in the share of state industrial parks has remained. In terms of the number of projects, private and state parks were almost equal: 75 and 71, respectively.

The analysis shows that, compared to 2015 , in the current year all the main economic indicators of the industry have grown. The number of residents placed in operating parks increased by 196 and reached 1,870 companies that created more than 104,000 jobs (an increase of $25 \%$ compared to the same indicator in 2015).

Total investments in the creation of infrastructure in industrial parks by 2016 reached 134 billion rubles (according to data from 104 industrial parks), and total investments in the creation of new industries amounted to 574 billion rubles. Average specific investments in infrastructure reached 7.8 million rubles per hectare. The specific attracted investment in production remained at the level of 2015 values - 31 million rubles on 1 ha. The total ratio of attracted investments in production to investments in infrastructure, according to aggregate data, by 2016 has become even more efficient, reaching values of 1 to 7.5 rubles.

The pace of industrial development confirms the important role of industrial parks as an effective tool for the territorial development of the reproduction system of industrial real estate.

\section{Materials and Methods}

\subsection{Methodical approach to the reconstruction of industrial parks}

The question of the feasibility and limits of the reconstruction is complicated, and in each specific case it needs to be solved according to specific conditions. To justify the reconstruction of the existing enterprise and the choice of the most effective variant of it, the calculation procedure proposed by the author, presented in Figure 1. 
Considering the above, the integral cost criterion should include the sum of capital investments and current operating costs (without depreciation) for the accepted assessment period $\tau$ :

$$
C_{\text {int }}^{\tau}=\sum_{t=1}\left(K_{t}+C_{t}-A_{p t}\right) \rightarrow \min
$$

To take into account the economic disparity in costs related to different years of the period $\tau$, the indicators $K_{t}, C_{t}, A_{p t}$ of each year are multiplied by the coefficients $B_{t}$. Essentially, by such an operation, the considered feedback costs are additionally introduced into the integral criterion: communications arising in the national economy as a result of diverting capital investments from a limited common source. The final integral cost criterion is as follows [5]:

$$
C_{\text {int }}^{\tau}=\sum_{t=1}\left(K_{t}+C_{t}-A_{p t}\right) \times B_{t} \rightarrow \min
$$

Indicator (2) is a dynamic analogue of the static criterion of reduced costs.

The criterion of the integral effect reflects the difference of the integral results:

$$
E_{\text {int }}^{\tau}=\sum_{t-1}^{\tau}\left[P_{t}-\left(K_{t}+C_{t}-A_{p t}\right)\right] \times B_{t} \rightarrow \max
$$

If in formula (2) we consider that the difference $P_{t}-C_{t}$ is the profit $M_{t}$, then the integral effect formula can be rewritten in the form:

$$
E_{\text {int }}^{\tau}=\sum_{t-1}^{\tau}\left(M_{t}+A_{p t}-K_{t}\right) \times B_{t} \rightarrow \max
$$

By means of the coefficient $\mathrm{B}_{\mathrm{t}}$, the criteria reflect additional inflows of the circulation effect for the period $\tau$ associated with the implementation of the option being evaluated. In general, the criterion of the integral effect reflects the entire table of the total regional purchase of direct and indirect national economic consequences of the adoption of a particular decision, which manifest themselves over a long period of evaluation.

In contrast to the static indicator of reduced costs, capital investments in the composition of integral criteria (formulas 1-4) are taken to be complete for all cycles of creation and replacement of evaluated objects during the evaluation period. Integral criteria clearly reflect the balance of all investments with depreciation inflows Art, which are considered here in their natural role as sources of financing of capital investments. The coefficients $B_{t}$ reflect the differences in the dynamics of capital investments and depreciation inflows. In cases where the evaluation period $\tau$ ends with the last year of the facility, the sum of depreciation inflows $A_{p t}$ becomes equal to the nominal capital investment $K_{t}$ for the period $\tau$, and the integral effect criterion (3) turns into accumulated profit $\mathrm{M}_{t}$ plus the effects of the circulation of this profit and temporarily released depreciation deductions. Particular attention is paid to the state of fixed assets, the degree of their physical and moral wear and tear, which largely determines the necessary depth of reconstruction of an industrial enterprise.

The potential effect of reconstruction is largely determined at the pre-design stage based on an analysis of the state of the existing industrial enterprise, technological processes and the possibilities for their improvement. At this stage, first of all, it is necessary to identify those nodes, the reconstruction of which will increase the production capacity of the industrial park as a whole. 


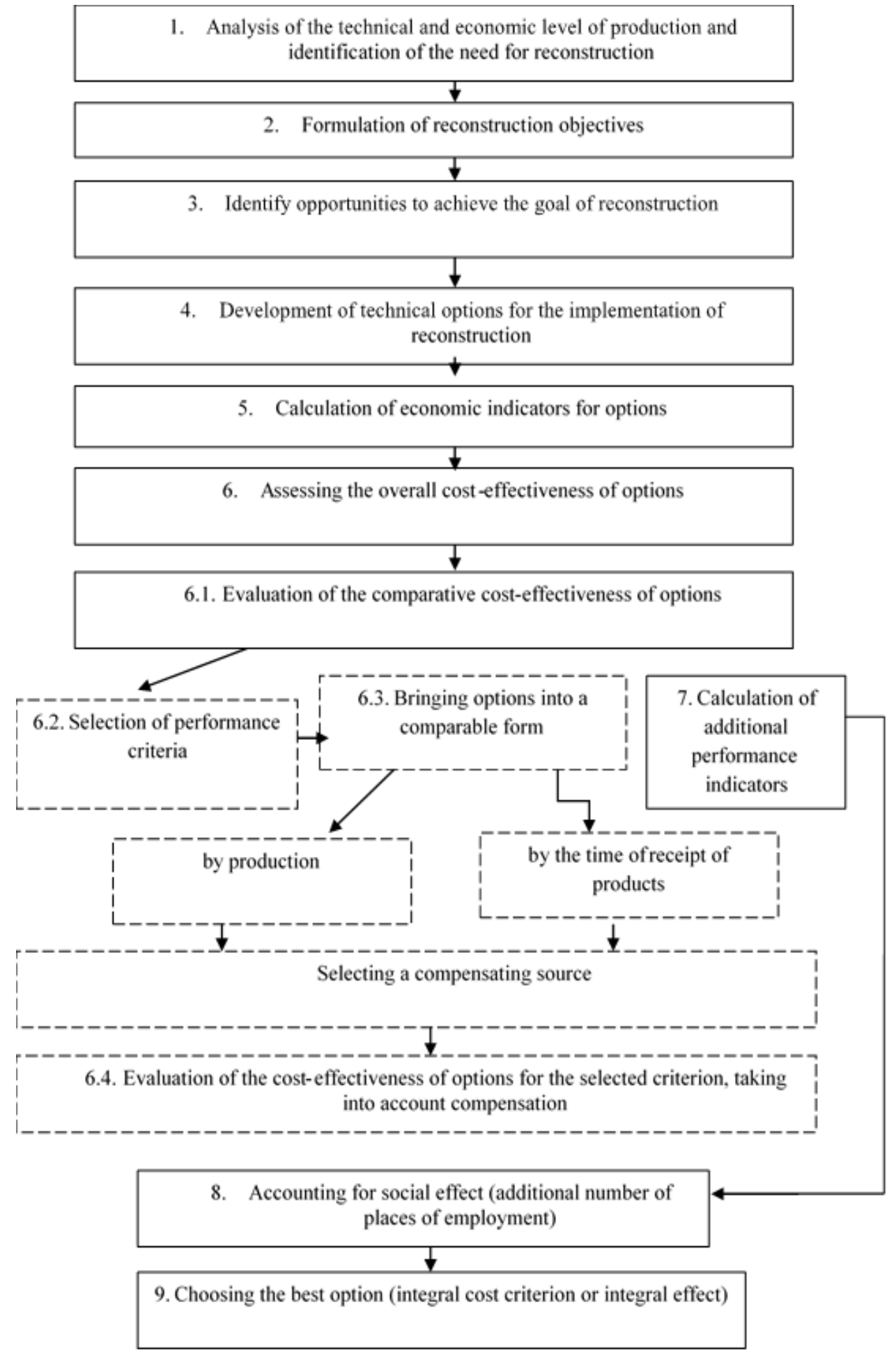

Fig. 1. The procedure for calculating the effectiveness of the reconstruction of the existing enterprise included in the structure of the industrial park. 
During the reconstruction of the industrial park of the type "brownfield" can be carried out:

- expansion of individual buildings and structures of the main, auxiliary and servicing purposes in cases where a new high-performance and more advanced technical equipment can not be placed in existing buildings;

- construction of new and expansion of existing workshops and auxiliary and service facilities in order to eliminate imbalances;

- construction of new buildings and structures of the same purpose in return for those liquidated in the territory of the existing industrial park, the further operation of which, due to technical and economic conditions, was considered inexpedient.

During the reconstruction should be provided:

- an increase in the production capacity of the industrial park, primarily due to the elimination of disproportions in technological units;

- introduction of low-waste, waste-free technologies and flexible industries;

- reducing the number of jobs and increasing productivity;

- reduction of material consumption of production and production costs;

- increasing capital productivity and improving other technical and economic indicators of the existing industrial park.

The reconstruction of existing industrial enterprises gives a greater economic effect than new construction, but also requires significant capital investments. In principle, IP reconstruction is usually more effective than new construction. When it costs the cost of restructuring only a part of the narrowest parts of an industrial enterprise, the effect of better utilization of all its links is achieved.

Infrastructure costs are also less with reconstruction, since we are talking about an existing company. At the same time, the cumulative national economic effect of reconstruction compared with new construction is less, since there is still no complete renovation of the industrial enterprise. In addition, the reconstruction carried out on the industrial site of the operating enterprise inevitably complicates its current work and for a certain period usually leads to a temporary decrease in the volume of output.

The economic efficiency of reconstruction is determined using methods and indicators of general and comparative efficiency. However, there are a number of features associated with the specific goals of its implementation.

\subsection{Methodical approach to the modernization of industrial parks}

The modernization of existing industrial parks includes a set of measures to improve the technical and economic level of individual industries, workshops and sites based on the introduction of innovations of modern information technologies and automation of production, modernization and replacement of outdated and physically worn-out equipment with new ones more productive, as well as improving the general production plant and support services.

Modernization of existing industrial parks is carried out on projects and estimates for individual objects or types of work, developed on the basis of a single feasibility study and in accordance with the plan for improving the technical and economic level of the industry (sub-industry), as a rule, without expanding production areas [6-10].

The goal of modernizing existing industrial parks is to create innovative production, which will increase production capacity, produce competitive products and improve their quality while increasing productivity and reducing jobs, reducing material consumption and cost of production, saving material and fuel and energy resources, and improving other technical -economic indicators of the industrial park as a whole [11-13]

When modernizing the existing industrial parks, installation can be carried out additionally on existing production areas of equipment and machines, the introduction of 
automated control and monitoring systems, the use of modern information technologies and television and other modern facilities in production management, modernization and technical reorganization of environmental objects, heating and ventilation systems, connection of enterprises, workshops and installations to centralized sources of heat and electricity power supply. At the same time, partial restructuring and expansion of existing industrial buildings and structures, due to the dimensions of the new equipment being placed, and expansion of existing or construction of new utility and maintenance facilities (for example, storage facilities, compressor rooms, boiler houses, oxygen and other facilities) are allowed, if this is related with ongoing technical upgrading activities.

Savings conditional fixed costs by reducing the duration of construction is determined by the formula:

$$
\mathrm{S}_{\mathrm{c}}=(0,01 \mathrm{q}+0,15 \mathrm{t}+0,5 \mathrm{n}) \times 0,01 \mathrm{C} \times\left(1-\mathrm{T}_{2} / \mathrm{T}_{1}\right),
$$

where $\mathrm{q}, \mathrm{t}, \mathrm{n}$ - the share of costs of construction and installation work, respectively, on materials, machine operation and overhead costs; $\mathrm{C}$ - the cost of construction and installation works; T2 / T1 - the duration of construction options; $1-\mathrm{T} 2 / \mathrm{T} 1=0.025$, according to comparative data of industrial real estate (for example, chemical and petrochemical industry).

The economic effect of the early commissioning of industrial real estate as a result of reducing the duration of construction is determined by the formula:

$$
E_{f}=q_{i r r} \times A \times\left(T_{1}-T_{2}\right),
$$

where $q_{\text {irr }}$ - internal rate of return;

A - the cost of fixed assets put into operation (here we should adopt a coefficient equal to 0.33 for the enterprises of the chemical and petrochemical industry).

The construction company should calculate the following indicators of the economic efficiency of the use of projects for the organization and production of works, reflected in the results of its production and business activities:

- $\quad$ saving labor costs $\Delta \mathrm{r}$;

- $\quad$ increase in labor productivity $\Delta \mathrm{B}$;

- $\quad$ profit increase $\Delta \mathrm{P}$;

- reduce the cost of construction and installation works $\Delta \mathrm{C}$;

- saving material resources $\Delta \mathrm{M}$.

\section{Conclusions and practical recommendations}

As an example of assessing economic efficiency (Table 1), we consider a section of the business plan for organizing the construction of an oil pipeline, which is part of an industrial (industrial) park, in the section from 1569 to $1978 \mathrm{~km}$ in the Mari Republic and the southern part of Kirov Oblast, with natural borders from r. Vyatka to $\mathrm{r}$. Vetluga diameter of the pipeline is $1020 \mathrm{~mm}$ [8]. From the point of view of construction conditions, the route should be classified as medium complexity.

The route crosses a significant number of beams, rivers, on the western part of the route, construction is complicated by weakly bearing soils that require laying roads, about half the length of the route requires clearing of vegetation.

The construction of the pipeline is carried out in three sections (streams): the length of section 1 from 1569 to $1593 \mathrm{~km}$ and from 1719 to $1807 \mathrm{~km} \mathrm{-} 112 \mathrm{~km}$; Section II from 1807 to $1903 \mathrm{~km}$ - $96 \mathrm{~km}$; Section III from 1903 to $1978 \mathrm{~km}-75 \mathrm{~km}$. 
Table 1. Initial data for calculation.

\begin{tabular}{|c|c|c|c|}
\hline \multirow{2}{*}{ Indicators } & \multirow{2}{*}{$\begin{array}{l}\text { Unit of } \\
\text { measurement }\end{array}$} & \multicolumn{2}{|c|}{ Compare options } \\
\hline & & base & new \\
\hline Estimated cost of the object & million rubles & - & 7500 \\
\hline Material costs & million rubles & 4150 & 4150 \\
\hline Basic wage & million rubles & 415.2 & 407,2 \\
\hline The cost of operating machinery & million rubles & 1237.4 & 1074.5 \\
\hline $\begin{array}{l}\text { Overhead costs depending on: } \\
\text { basic salary }\end{array}$ & million rubles & 62.3 & 61.1 \\
\hline \multicolumn{4}{|l|}{$(415.2 \times 0.15=62.3 ; 407.2 \times 0.15=61.1)$} \\
\hline \multirow{2}{*}{$\begin{array}{c}\text { Labor intensity } \\
(91.65 \times 0.6=55 ; 89.9 \times 0.6=53,4)\end{array}$} & million rubles & 55 & 53.9 \\
\hline & & \multirow[b]{2}{*}{91.65} & \multirow[b]{2}{*}{89.9} \\
\hline Labor costs & $\begin{array}{l}\text { million person- } \\
\text { day }\end{array}$ & & \\
\hline Capital investment in basic production assets & million rubles & 2527.6 & 2523.6 \\
\hline Duration of construction & year & 0.75 & 0.67 \\
\hline
\end{tabular}

The economic effect obtained as a result of the implementation of a more advanced project for the organization of construction is determined by the formula:

$$
\mathrm{E}=\mathrm{C}_{1}-\mathrm{C}_{2}
$$

For each of the options it will be:

$\mathrm{C}_{1}=5919.9+0.15 \cdot 2527.6=6299$ million rubles,

$\mathrm{C}_{2}=5746.7+0.15 \cdot 2523.6=6125.2$ million rubles,

$\mathrm{E}=6299-6125.2=173.8$ million rubles.

In addition to the direct economic effect of reduced costs, the cost of semi-fixed costs of construction company Eu is achieved as a result of a reduction in the duration of construction.

Partially fixed expenses $\mathrm{N}$ are accepted:

- on overhead charge: $\mathrm{N}_{\mathrm{i}}=117.3 \times 0.5=58.7$ million rubles;

- on the cost of operating machines and mechanisms:

$\mathrm{N}_{\mathrm{o}}=1.237 .4 \times 0.15=185.6$ million rubles;

- on materials costs: $\mathrm{N}_{\mathrm{m}}=4150 \cdot 0.01-41.5$ million rubles;

Total $\mathrm{N}=285.8$ million rubles.

Then $\mathrm{E}_{\mathrm{c}}=\mathrm{N} \times(1-\mathrm{T} 2 / \mathrm{T} 1)=285 \times(1-0.67 / 0.75)=30.6$ million rubles.

The savings from the operation of the object for the period of early commissioning of Eph will amount to $\mathrm{E}_{\mathrm{f}}=7500 \times 0.15(0.75-0.67)=90$ million rubles.

The total economic effect will be:

$\mathrm{E}+\mathrm{E}_{\mathrm{c}}+\mathrm{E}_{\mathrm{f}}=173.8+30.6+90=294.4$ million rubles.

The duration of construction according to the norms, taking into account the coefficient for transitions, is 15 months (adopted by the largest construction site). At the estimated pace of construction, taking into account the policy deadlines established by PJSC Stroytransgaz, the duration of construction is 8 months.

Recommendations on the composition and equipment of complex linear construction and installation flows for the construction of trunk pipelines with a diameter of 1020, 1220 and $1420 \mathrm{~mm}$ in various conditions, approved by the Ministry of Industry and Trade of the Russian Federation, were adopted as a standard. 
The pace of work was adopted according to the technological maps of the work of the insulation-laying column, the insulation is made with a polymer tape. The duration of work on the standard 9 months. Only the main building machines and mechanisms are taken into account when working in one shift. Execution of works in accordance with the project of the organization of construction allows to reduce the construction time, reduce the estimated cost and the cost of construction and installation and labor costs compared to accepted.

\section{References}

1. Industrial parks of Russia. Industry Review, Issue four (AIP, Moscow, 2016)

2. A. Grebenshchikov, Methodological foundations of the formation and management of the total cost of ownership of various types of industrial parks in the life cycles of their reproduction (Publishing House MISI-MGSU, Moscow, 2017)

3. V.S. Grebenshchikov, M.S. Guschina, Young scientist 13(147), 277-279 (2017)

4. V.S. Grebenshchikov, Methodological foundations of the formation and management of the total cost of ownership of various types of industrial parks in the life cycles of their reproduction (MISI-MGSU, Moscow, 2017)

5. V.N. Morozov, Economy, business, environment 4(28), 34 - 37 (2006)

6. C. Armstong, Project Portfolio Selection Methods (University of Wisconsin, Platteville, 2004)

7. R. Boyer, Problemes economic 2653, 15-23 (2000)

8. P. Cooke, Knowledge Economies: Clusters, Learning and Cooperative Advantage (Routledge, London, 2002)

9. A.D. Maksimov, T.A. Maximov, Economy of the region 3, 70-78 (2009)

10. D. Dohse, Research Policy 29, 11-33 (2000)

11. R. Horvdenski, C. Sadowska-Snarska, Spatial dimension of socio-economic transformation processes in Central and Eastern Europe on the turn of the 20th century 2, 35-43 (2001)

12. J. Kitowski, Spatial dimension of socio-economic transformation processes in Central and Eastern Europe on the turn of the 20th century 2, 28-35 (2001)

13. C. Ketels, The Cluster Initiative Green Book (Christian, St Peterburg, 2003) 